\title{
Durability of repair mortars used in restoration of a Sardinian coastal tower: assessment after ten years Paola Meloni ${ }^{a}$, Gianfranco Carcangiu ${ }^{b}$, Marcella Palomba ${ }^{b}$, Stefano Enzo ${ }^{c}$, Maura Carboni $^{\mathrm{c}}$, Ombretta Cocco ${ }^{\mathrm{d}}$, Marta Casti ${ }^{\mathrm{d}}$, Arianna Murru ${ }^{\mathrm{d}}$, Alessio Farci ${ }^{\mathrm{e}}$, Alessandro Ruggieri $^{\mathrm{a}}$
}

${ }^{a}$ Università degli Studi di Cagliari, Dipartimento di Ingegneria Meccanica, Chimica e dei Materiali, Cagliari, Italy, paola.meloni@unica.it, ruggieri.alessandro@libero.it ${ }^{b}$ Consiglio Nazionale delle Ricerche - Istituto di Scienze dell’Atmosfera e del Clima, Bologna, Italy, g.carcangiu@isac.cnr.it - m.palomba@isac.cnr.it, 'Università degli Studi di Sassari, Dipartimento di Scienze Chimiche e Farmaceutiche, Sassari, Italy, enzo@uniss.it, maucarboni@uniss.it, ${ }^{\mathrm{d} U n i v e r s i t a ̀ ~ d e g l i ~ S t u d i ~ d i ~ C a g l i a r i, ~ D i p a r t i m e n t o ~ d i ~ I n g e g n e r i a ~ C i v i l e, ~ A m b i e n t a l e ~ e ~ A r c h i t e t t u r a, ~ C a g l i a r i, ~ I t a l y, ~}$ ombretta.cocco@unica.it, marta.casti@unica.it, ${ }^{\mathrm{e}}$ Fluorsid S.p.A., Cagliari, Italy, a.farci@fluorsid.com

\begin{abstract}
This study reports the results of investigations on conservation conditions of an ancient tower, called Torre del Pozzo, located in the S-W coast of Sardinia, restored about ten years ago. The tower suffers from serious problems related to vulnerability of building materials, particularly limestone and sandstones and aerial lime mortar with poor physical-mechanical properties. Over the centuries the materials were subjected to aggressive actions (wind corrasion and salt crystallization) causing an intense erosion of the walls with consequent partial collapse of the structure. About ten years ago a restoration involved the mortars and only the replacement and integration of ashlars deteriorated. After about 10 years from this intervention, some inspections have been carried out in order to assess the effectiveness of the intervention and the state of preservation of the tower. This paper focuses on analyses and tests carried out to assess condition and durability of the repair mortars.
\end{abstract}

Keywords: coastal tower, repair mortar, salt crystallization, Sardinia.

\section{Introduction}

The protection system through the coastal towers of Sardinia, developed organically especially under Spanish rule, between the sixteenth and seventeenth centuries. The towers were built on promontories dominating the area, having the specific function of guarding the coasts and maritime trade against external aggressions.

The towers positions were planned on the basis of their specific functions: control of territory, protection of the shipping trade, transmission of military information, surveillance of water sources. Promontories were selected dominating the area that offered the best possible visibility, so that each tower could easily communicate visually with the two adjacent ones.

The projects of the towers were set, in most cases, on the criteria of maximum constructional simplicity and reduced cost; for this reason the type adopted was a circular base and a cylindrical or truncated cone shape.

The rock-types used in the construction of the towers are extremely heterogeneous because, in order to minimize manufacturing costs, local geomaterials, having physical-mechanical characteristics not always optimal, were privileged. The mortars were made with a putty 
lime, prepared on site or brought from neighboring villages and using local sand, also of marine origin, and frequently sea water. The same materials used for the bedding mortar, were then used for coating both the inside and the outside of the towers.

Some of these coastal towers, historical evidence of the defensive system of the island, have been restored because their critical conservation status. The monitoring of the restoration work, carried out about 10 years ago on the so-called Torre del Pozzo, subject of this study, provided useful informations for future restoration interventions, especially in relation with the choice of more durable mortars. The absence of surface protection, for a long time, has resulted in the progressive and severe degradation of the underlying structure. The main objective of this work is to assess the state of conservation of the materials fitted in the last restoration carried out about ten years ago.

\subsection{Localization, geological setting and state of conservation}

The Torre del Pozzo is situated on a promontory at $19 \mathrm{~m}$ above sea level, in the SW coast of Sardinia. It is architecture with a circular base diameter of about $15 \mathrm{~m}$ and a height of $11 \mathrm{~m}$. Torre del Pozzo is located in the village of the same name, part of the coastal villages of Cuglieri, in the northern part of the Sinis Peninsula. It is located on a rock panoramic (the Whale), surrounded by a shallow and slightly sloping to the sea (Fig. 1).

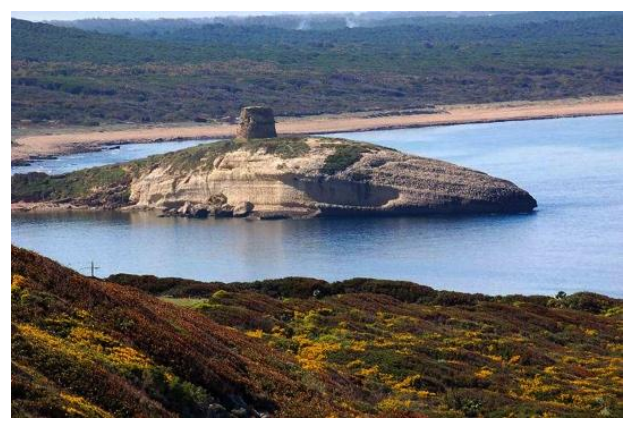

Fig. 1- Torre del Pozzo at present

The geological formations that characterize this area are Cenozoic and Quaternary sedimentary
(1-3) and volcanic formations (4-5). Geological setting of the area is characterized by the presence of terrains belonging to the Miocene (Serravalian) and late Pleistocene marine facies, consisting of biomicritic limestones and beach conglomerates, somewhere richly fossiliferous, attributable to transgressive marine phases (Tyrrhenian).

The artifact was in severe degradation conditions, almost in a state of ruin (Fig. 2).

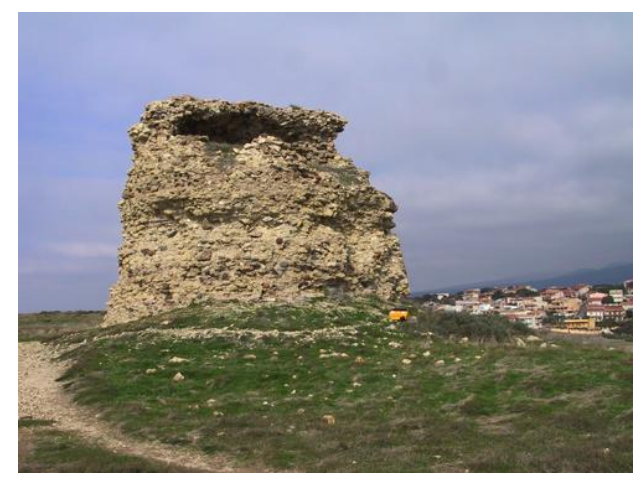

Fig. 2- Torre del Pozzo before the restoration

Along the east side of the tower, although protected from the wind, the protective plaster had almost entirely disappeared. Along the wall surfaces, the stone materials showed obvious signs of erosion and washouts; the original lime mortars, though not so friable and sufficiently firm to the touch, in many cases, were no longer able to keep welded the ashlars. This fact is mainly due to the strong reduction of their thickness resulting from the marine erosion.

About 10 years ago, the critical conditions of the Tower required an urgent conservative action for containing the progress of degradation and the risk of collapse. The restoration works mainly focused on the repositioning and the rejoining of the most degraded wall and flaking portions (Fig. 3).

In particular, the base of the Tower, affected by a substantial back weathering of surfaces, and all the masonry were repaired recycling collapsed materials for the consolidation and recovery of the geometry of the structure. A bedding NHL based mortar was made and loose materials 
found at the base of the tower, were sieved and used as aggregates.

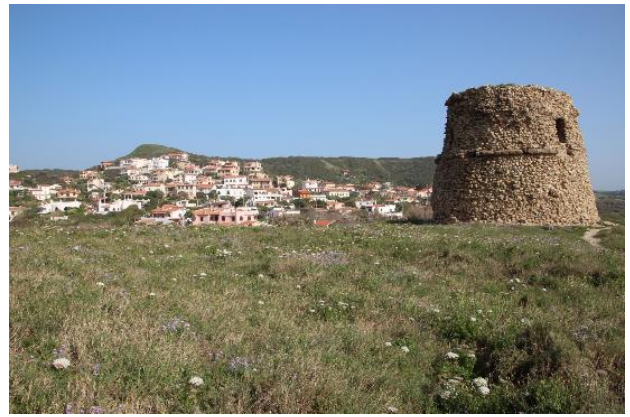

Fig. 3- Torre del Pozzo restored

\section{Materials and methods}

Several lithotypes form the walls of Torre del Pozzo, prevalently sandstones and biomicritic limestone but also basalt/andesitic ashlars are present (Fig. 4).

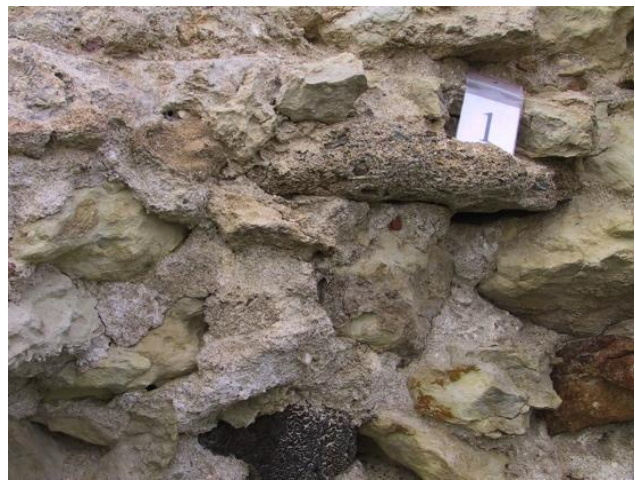

Fig. 4 - Detail of Torre del Pozzo building materials

Before the restoration, sampling was carried out both on ashlars and mortars. The collected samples were characterized on physicalmechanical, mineral-petrographic, microstructural and textural point o view. The present study focuses on the performance of mortars because no surface protective or consolidating action were carried out on stone materials.

Optical microscopy studies were performed by a Zeiss Optical Microscopy Axioscop 40 equipped with an AxioCam MRc5; mineral studies were carried out by a Rigaku Miniflex II X-ray powder diffractometer, operating with a $\mathrm{CuK} \alpha$ monochromatic radiation at $15 \mathrm{kV}-30 \mathrm{~mA}$; Mercury Intrusion Porosimetry (MIP) technique, was applied by a Micromeritics Autopore IV 9500 apparatus; SEM observations were made using a Zeiss Evo LS15 electron microscopy, equipped with a LaB6 electron source.

\section{Results and discussion}

\subsection{Stone materials}

Fig. 5 depicts a microphograph of the prevalent biomicritic limestone. A lime mud (micrite) surrounds and supports fossiliferous skeletons, mostly of crinoids (white fragments) and brachiopods (curved fragments), although bryozoans and other organisms can be present.

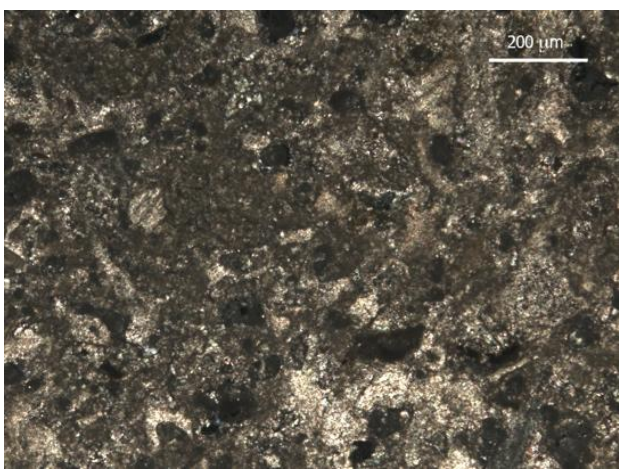

Fig. 5 - Microphotograph of biomicrityic limestone

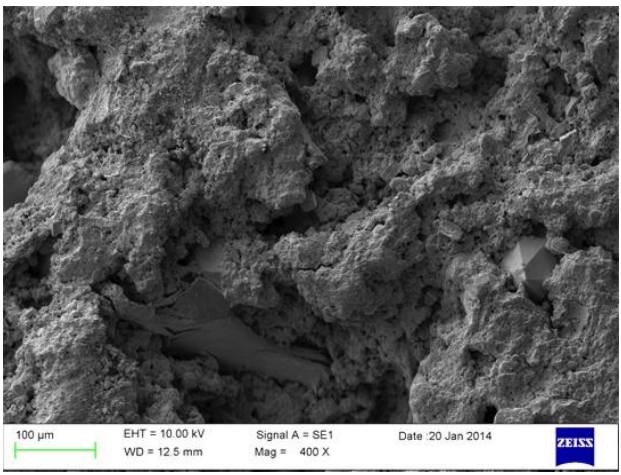

Fig. 6 - SEM image of biomicritic limestone

Fig. 6 shows the microstructure of the biomicritic limestone. As can be seen, it exhibits a high porosity, presence of silica minerals and phyllosilicates along with very fine carbonatic matrix. The same mineralogical composition is assessed by XRD analyses. 
This lithotype appears intrinsically not durable, both for the poor mechanical properties (compressive strength of between 10-15 $\mathrm{MPa}$ ) that for the high porosity (35\%).

\subsection{Mortars}

\subsubsection{Original mortars}

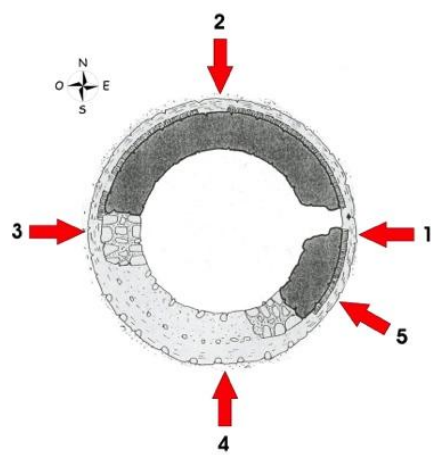

Fig. 8 - Sampling of original mortars

In all the sampling points, indicated in Fig. 8, the finishing plaster was completely absent.

The analysis of the original bedding mortars showed that they are mixtures of aerial lime binder and aggregates in the size of large and medium sands (prevalent) and gravels with a maximum size of about $10 \mathrm{~mm}$. The aggregates are of local origin or originate from the decomposition of limestones, sandstones outcropping on site, fragments of lavas (basalt, basanite, andesites and trachytes), rare fragments of volcanic tuffs. White lumps are rather diffuse, about $5 \mathrm{~mm}$ sized, originating from a nonperfect homogenization of the components.

The binder/aggregate ratio in the original mortars has been evaluated of 1:2.

Fig. 9 shows a representative XRD spectrum for the original mortars taken at points indicated in Fig. 8. MIP investigations have revealed a total porosity of about $40 \%$ for the mortars exposed to sea side and $25 \%$ for those in the innermost protected side. Figure 10 shows pore sizes distributions of these two mortars
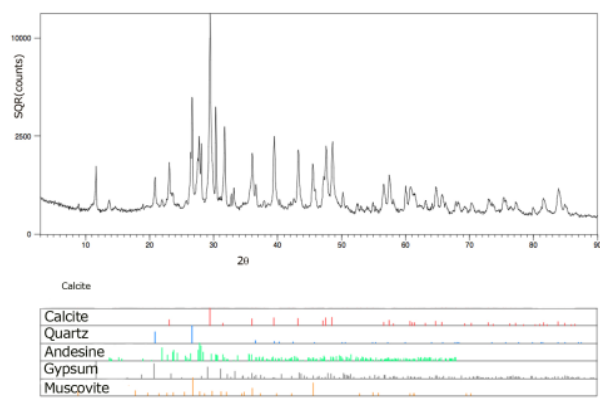

Fig. 9 - XRD pattern of original mortar
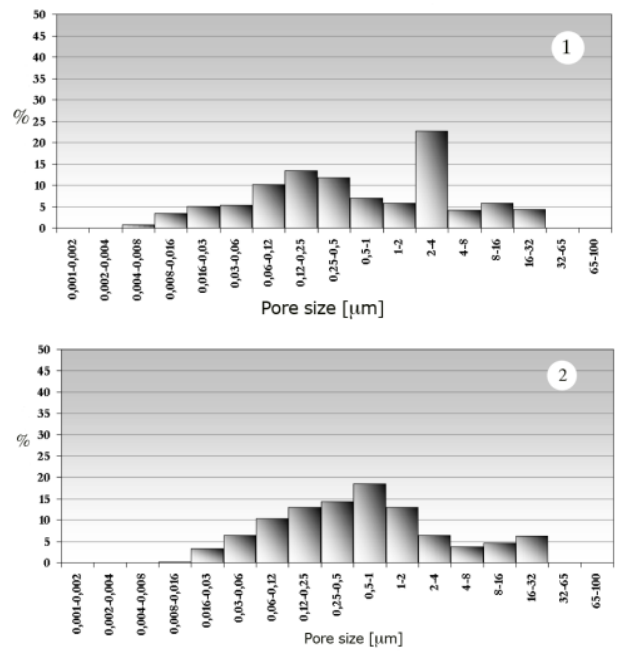

Fig. 10 - Pore sizes distribution of original mortars: 1) sea side; 2) protected inside

One can observe a shift of the distribution towards classes of larger pores, in the case of mortars critically exposed to the sea side.

The major problem related to the conservation of coastal towers can be identified in the strong aggressiveness of the marine environment, especially in areas particularly exposed to strong winds. The loss of material, resulting in the erosive action and therefore, the thinning of the wall structures, involves the consumption of mortars and detachment of ashlars, even the most intrinsically resistant like basalt. The original mortars, as stated above, are still sufficiently compact to the touch, typical texture of those made with ordinary aerial lime. The lack of a surface coating (only a few shreds found at that time) and high porosity of mortars, 
induced by the salt crystallization, have been crucial factors to the degradation of the fortification.

In fact, repeated cycles of absorption of salt solutions and evaporation, as well as cycles of crystallization and solvation (ie, dissolution of crystals for water inlet), contribute to progressively increase the amount of salt within the material with possible creation of preferential accumulation zones.

The deterioration of the material from the surface generally begins with chalking, in the case of mortars; crystallization of salts from the inside then continues to the stone-mortar interface, exerting forces that lead to the crumbling and/or detachment of the coating. The structure, devoid of such coating becomes more vulnerable to the actions of successive attacks by the same agents.

\subsubsection{Repair mortars}

The mix design involved the use of natural hydraulic lime (Romana lime, Brigliadori furnaces) of beige color, which, besides giving greater durability to the mortar, allows discriminating, even for the different colors, the original mortars from repair ones. The final binder is then consisting of: $65 \%$ natural hydraulic lime, putty lime $30 \%$ and $5 \%$ of White Cement (Class I 52.5). The binder can therefore be likened to NHL-Z according to UNI EN 459$1[6]$

The aggregates were obtained by sieving outcropping materials in the proximity of the tower and by the debris produced by the collapse of parts of the same. After sorting and sifting, they were subjected to washing before being inserted in the mortar. The amount of water in the mixture was varied in relation to the necessary workability. The ratio of the aggregate / binder used was 3:1.

At a distance of 10 years from the restoration, some mortar fragments have been analyzed. The visual inspection showed no macroscopic phenomena of detachment, erosion and/or cracking of mortar, which is shown very tied to the stone substrate (2 as indicated in Fig.12).
XRD investigations have identified the following crystalline phases: Calcite, Quartz, Plagioclase, Sanidine and Halite. Fig. 12 shows a detail of the wall with indicated the two types of mortars: the original mortar (1) and the repair one (2). We observe a correct choice of the texture of the repair mortar, with a slightly darker hue that of the original mortar.

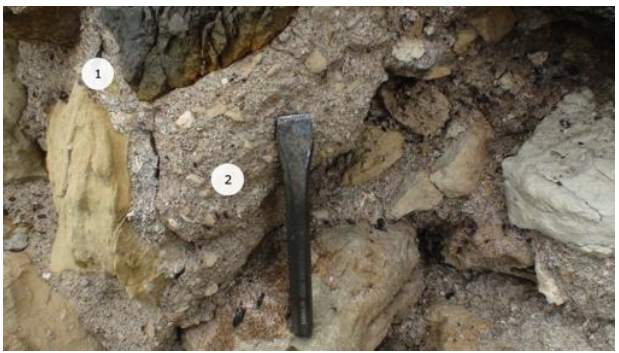

Fig. 11 - Detail of masonry with original (1) and repair mortars (2)

The analysis under a binocular microscope and optical showed a binding matrix rather homogeneous, microcrystalline, with rare cracks. No significant detachments can be observed at the binder-aggregate interface (transition zone). The macroporosity (pores of diameter greater than $150 \mu \mathrm{m})$ generated by air incorporated during the laying, is about $10 \%$; therefore the microvoids are responsible to induce the total porosity of the mortar. A typical porogramma mortar, after ten years of exposure to aggression saline and wind erosion, is shown in Fig. 11.

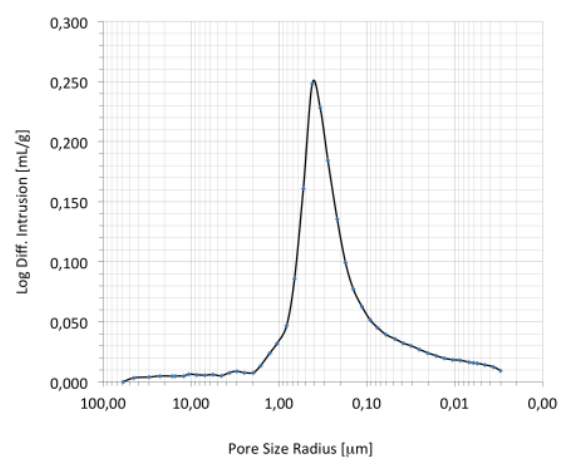

Fig. 12 - Pore sizes distribution of repair mortar 
We observe a normal distribution extended in the range between $45 \mu \mathrm{m}$ and $0.03 \mu \mathrm{m}$ with median radius equal $0.3 \mu \mathrm{m}$.

The total porosity (average of 6 specimens) amounted to $27,2 \% \pm 3,4$. The values of porosity are comparable to those of a mortar based on NHL.

In order to evaluate the durability of the repair mortars, in place now for about 10 years and continually subject to aggression by salts transported within the matrix, the pressure of $\mathrm{NaCl}$ crystallization was calculated using the Everett's thermodynamic model (7), modified according Fitzner and Snethlage (8). The application of the model allows providing an assessment of the forecast on the durability of porous materials subjected to stresses exerted by disintegrating ice or salts.

The equation that allows evaluating the pressure of crystallization is as follows:

$$
\mathrm{P}_{\mathrm{c}}=2 \gamma *(1 / \mathrm{r}-1 / \mathrm{R}) * \mathrm{~V}_{\mathrm{r}} / \mathrm{V}
$$

for an idealized pore system with two classes of interconnecting pores of radius $r$ and $R$ (with $R>$ $r)$ that can be further simplified and modified in:

$$
\mathrm{Pc}=2 \gamma^{*}(1 / \mathrm{r})^{*} \mathrm{Vr} / \mathrm{V}
$$

assuming $\mathrm{R}>>\mathrm{r}$ and where:

$\gamma$ is the interfacial tension of the salt;

$r$, is the mean radius of each pore size class;

$\mathrm{V}_{\mathrm{r}}$ is volume of intruded $\mathrm{Hg}$ for pore of $\mathrm{r}$ radius;

$\mathrm{V}$, is the total volume of intruded $\mathrm{Hg}$.

The calculation was made by considering the interfacial tension of $\mathrm{NaCl}(\gamma)$ of 80 dynes $/ \mathrm{cm}$. The calculated value is equal to $2.5 \mathrm{MPa}$.

This value is higher than the theoretical tensile strength of the mortar and therefore the data derived from the application of the model would lead to assume a low durability of the mortar itself.

However, the value calculated by porosimetry MIP should be appropriately corrected to take account of:

macropores of diameter greater than $60 \mu \mathrm{m}$.
- presence of porous aggregates that contribute to accommodate disintegrating tensions.

- physical-mechanical characteristics of the binder matrix.

- real possibility of permeation of salt solutions in very small pores, considering the surface tension of the solution, with overestimation of the disruptive effects.

\section{Conclusion}

Local geomaterials, consisting of rock types inherently vulnerable such as sandstones and limestones, and aerial lime mortars have played a critical role in building and in the life of the tower.

The restoration has focused on the preparation and implementation of hydraulic mortars, as restoring the original ones, because of the extreme aggressiveness of the environment.

After about 10 years the general state of conservation of the weir and in particular that of the mortars was evaluated. Their function is strategic to the static stability of the building and for the durability since the intervention intentionally has not provided the execution of a plaster for the protection of the masonry.

The repair mortars are in good condition.

Their durability is also been estimated through the application of a physical model, based on the distribution of the pore sizes and on the crystallization pressure by $\mathrm{NaCl}$.

The applied model tends to overestimate the pressure crystallization if not properly calibrating the experiments in climatic chamber with the observations on real samples on site, exposed for a long time to severe environmental conditions.

\section{Notes}

Work performed within the project " I Beni Culturali e la prova del tempo: strategie innovative per la Conservazione mediante il controllo di processi minerogenetici e inibitivi".

Funding from the Regional Law 2007, n. 7: "Promozione della Ricerca Scientifica e 


\section{References}

Comaschi-Caria I. (1951). Osservazioni paleontologico-stratigrafiche sul Miocene e sul Quaternario marino della zona di Pittinuri a nord del golfo di Oristano (Sardegna). Rend. Sem. Fac. Sc. Univ. Cagliari, XX, pp. 1-16.

Cherchi A. \& Montadert L. (1984). Il sistema di Rifting oligo-miocenico del Mediterraneo occidentale e sue conseguenze paleogeografiche sul Terziario sardo. Mem. Soc. Geol. It., 24, pp. 387-400.

Ulzega A. \& Ozer A. (1982) - Comptes-Rendus de l'Excursion-Table rond sur le Tyrrhénien de

Sardaigne oriéntale. INQUA, p. 110, Cagliari.

Assorgia A., Beccaluva L., Deriu M., Di Battistini G., Gallo F., Macciotta G., Pinali L., Venturelli G., Vernia L., Zerbi M. (1981). Carta geopetrografica del complesso vulcanico del Montiferro (Sardegna centro-occidentale). Grafiche STEP, Parma.

Lorenzo Fedele, Michele Lustrino, Leone Melluso, Vincenzo Morra, Fosco D'Amelio (2007). The Pliocene Montiferro volcanic complex (central-western Sardinia, Italy): geochemical observations and petrological implications. Per. Mineral. 76, pp. 101-1.

UNI EN 459-1:(2010). Calci da costruzione - Parte 1: Definizioni, specifiche e criteri di conformità

Everett D.H.(1961). The termodynamics of frost damage to porous solids, Trans. Faraday Society, vol 57, pp. 1541-1551.

B. Fitzner, R. Snethlage (1982). Über Zusammenhänge zwischen Salzkristallizationsdrunk und Porenradienverteilungd, GP News Letter, vol.3, pp 13-24. 
